\title{
O PROCESSO DE TRANSFORMAÇÃO DO EXÉRCITO BRASILEIRO A PARTIR DA PERCEPÇÃO DE OFICIAIS DA FORÇA
}

\author{
Alexandre Santana Moreira ${ }^{1}$ \\ Valentina Gomes Haensel Schmitt ${ }^{2}$
}

\section{RESUMO}

O estudo visou analisar a percepção de oficiais militares, na condição de alunos da Escola de Comando e Estado-Maior do Exército (ECEME), acerca do corrente processo de transformação do Exército Brasileiro (EB). Para atingir os objetivos, foram realizadas pesquisas bibliográfica e de campo, que foramsucedidas da análise quantitativa dos dados coletados. Na etapa de pesquisa bibliográfica, o foco esteve na compreensão do problema de estudo, notadamente a partir da teoria da transformação organizacional. Para compreensão do problema, foram analisadas as dimensões estratégica, estrutural, tecnológica, humana, cultural e política (MOTTA, 2001). A pesquisa de campo envolveu a coleta de dados por intermédio da aplicação de questionário tipo survey, com cinco níveis de resposta na escala Likert, objetivando verificar a percepção dos indivíduos representados pela amostra em relação ao processo estudado e as dimensões de análise supracitadas. A amostra foi composta de oficiais, integrantes do corpo discente do curso de Altos Estudos da ECEME, obtendo 148 (cento e quarenta e oito) questionários válidos. $\mathrm{O}$ tratamento dos dados envolveu o uso da Análise Fatorial e Regressão Logística. Os resultados do estudo indicaram que os oficias percebem como de maior influência para a condução do processo de transformação na organização estudada as variáveis cultural, humana e estrutural. Em contrapartida, destacaram-se como as de maior influência a respeito da percepção (positiva ou negativa) acerca do processo as variáveis estratégica, tecnológica e humana. Ao final do estudo são apresentadas sugestões direcionadas ao entendimento do processo de transformação do EB, bem como proposições para gestores acerca de possibilidades para a sua condução e melhoria de processos.

Palavras-chave: Transformação organizacional; Gestão estratégica; Percepção; Organizações militares; Exército Brasileiro.

\footnotetext{
1 Possui graduação em bacharel em Ciências Militares pela Academia Militar das Agulhas Negras, AMAN, mestrado em Operações Militares pela Escola de Aperfeiçoamento de Oficiais, EsAO, doutorado em Ciências Militares pela Escola de Comando e Estado-Maior do Exército, ECEME. Rio de Janeiro - RJ. Brasil. E-mail: alex_smor@yahoo.com.br.

2 Professora na Universidad de Piura (Peru). Doutora em Administração pela Fundação Getúlio Vargas, FGV. Mestrado e bacharel em Administração pela Universidade Federal de Santa Catarina. E-mail: valentina.schmitt@udep.pe.
} 


\section{INTRODUÇÃO}

A transformação organizacional no ambiente da Defesa Nacional é assunto corrente nas principais Forças Armadas modernas, e o mesmo ocorre no Brasil. Tal fato é reforçado pela necessidade de identificar as modernas ameaças ${ }^{1}$ nas questões de Segurança e Defesa, tais como: a marginalidade social, as migrações descontroladas, o narcotráfico, o terrorismo, o crime organizado, as violações dos direitos humanos, a degradação do meio ambiente e as discriminações (COVARRUBIAS, 2005). Esses fatores favorecem a eclosão de conflitos, exigindo Forças Armadas preparadas e equipadas, a fim de bem desempenharem com prontidão suas funções sempre que necessário.

Os conflitos modernos vêm demandando que as Forças Armadas, e consequentemente os exércitos formatados para a Era Industrial, busquem a transformação a fim de se adequarem à realidade dos novos conflitos característicos da Era da Informação (DRUCKER, 2002). Assim, as Forças Armadas, de várias partes do mundo, estão implementando processos de inovação. Dentre os países de destaque em processos de mudança estão os do Estados Unidos da América (EUA), a Espanha e o Chile, seja em termos de gestão ou inserção de inovações tecnológicas. Cabe, contudo, destacar o papel do modelo americano de transformação da defesa, adotado por um número crescente de países (PRETORIUS, 2008).

No Brasil, a mudança recente é marcada fortemente pela criação do Ministério da Defesa (MD) em 1999, que veio a substituir o antigo Estado-Maior das Forças Armadas (EMFA). Essa primeira mudança na estrutura de gestão, fez com que ao invés de existirem três ministérios, com características exclusivamente militares - da Aeronáutica, do Exército e da Marinha - fosse instituída uma pasta focada em Defesa, conjugando as três Forças e o ambiente civil (SCHMITT e MARQUES, 2013). Uma das consequências da criação do MD foi a aproximação entre civis e militares, que acarretou na ampliação de discussões conjuntas e a revisão da Política de Defesa Nacional, a elaboração da Estratégia Nacional de Defesa e os estudos para a confecção do Livro Branco de Defesa Nacional (VASCONCELLOS, 2011). Emergiu a necessidade por conformação das Forças Armadas a essa nova realidade - em suas estruturas, gestão, materiais, etc.

O Exército Brasileiro (EB), uma organização pública, em consonância com o contexto posto, buscou o aperfeiçoamento da sua gestão no sentido de adaptação e proatividade. Reflexo das demandas por atualização, foi implementado o processo de transformação do EB, estabelecendo a Estratégia Braço Forte ${ }^{2}$ como norteadora de suas ações. A estratégia organizacional foi desdobrada, a priori, em sete vetores, quais sejam: a) Ciência e Tecnologia; b) Doutrina; c) Educação e Cultura; d) Gestão; e) Logística; f) Preparo e Emprego; g) Recursos Humanos. Ainda, a Estratégia Braço Forte foi desdobrada em dois programas relativos à articulação, o Programa Amazônia Protegida e o Programa Sentinela da Pátria, e dois programas relativos ao equipamento, o Programa mobilidade Estratégica e o Programa Combatente Brasileiro do Futuro/COBRA.

\footnotetext{
${ }^{1}$ As novas ameaças é um conceito estabelecido por Mary Kaldor, advogando que a guerra como prescrevia Clausewitz não era mais aplicável, pois os meios militares não visavam mais derrotar um Estado Nacional, mas enfrentar outras ameaças como conflitos étnicos, religiosos, tribais, entre outros.

${ }^{2}$ A Estratégia Braço Forte é o nome dado ao projeto de transformação do Exército Brasileiro.
} 
No âmbito da Escola de Comando e Estado-Maior do Exército (ECEME)³, o tema e seu aprimoramento tornaram-se uma constante entre alunos e oficiais nela alocados para o exercício da atividade profissional. Destarte, visualiza-se a relevância do estudo processo de transformação da Força Terrestre brasileira ${ }^{4}$, a partir de abordagens da transformação organizacional ${ }^{5}$, facilitando a compressão deste fenômeno atual nas organizações militares.

Diante do exposto, presente estudo analisou a percepção de militares alunos da Escola de Comando e Estado-Maior do Exército (ECEME) com relação aos fatores de influência no processo de transformação do Exército Brasileiro (EB). O entendimento dos oficiais acerca do processo em andamento na Força resulta da relação entre os sete vetores de transformação estabelecidos pela Força Terrestre e as dimensões da transformação organizacional (MOTTA, 2001).

\section{REFERENCIAL TEÓRICO}

\subsection{Transformação organizacional e o ambiente militar.}

No cotidiano das organizações, muito tem se falado sobre mudanças, em termos de cultura, desenvolvimento de novos produtos, recuperação de posição, administração com qualidade total, dentre outros (MINTZBERG, 2006). Contudo, é fato corrente que pode-se mudar facilmente um único produto ou uma pessoa, porém mudar uma estrutura organizacional ou uma visão coletiva requer um tratamento complexo (MINTZBERG et al., 2000). As abordagens acadêmicas, por seu caráter de complexidade, podem dificultar o gestor a adequar sua organização sob diferentes perspectivas. Cada gestor tende a usar a abordagem que melhor esteja adaptada a seu modo de proceder ou pela experiência que possuem, ressalta Mintzberg. A mudança organizacional envolve elementos tangíveis e intangíveis.

Em termos de gestão estratégica, existem forças que condicionam a formulação e implementação, que podem ser resumidas na estrutura organizacional, inovação tecnológica, liderança estratégica e cultura organizacional (HITT et al., 2002). A compreensão do processo de condução de estratégias facilita sua aplicação. Assim, a transformação pode ocorrer mediante diversas correntes, as quais balizam o entendimento e o desenvolvimento organizacional.

Diferentes são as nuances relacionadas aos processos predominantes, sejam esses derivados dos portes das organizações, ou da sua propriedade. Na administração pública, mesmo diante da existência de fortes crenças em relação à efetividade da prática regular do planejamento estratégico, há ainda uma limitação acerca da aprendizagem da instrumentalização, especialmente no que concerne a execução das ações propostas (SILVA e GONÇALVES, 2011). Mediante essa realidade, a transformação advém de um conjunto complexo, confuso, de muitas contradições. Farrel e Terriff (2002) defendem que as bases da mudança militar sejam a cultura, política e tecnologia. De outra parte, Motta (op. cit.), desdobra o processo em seis perspectivas, a saber: estratégica, estrutural, tecnológica, humana, cultural e política. Aqui optamos por analisar o processo priorizando a segunda abordagem, cuja explicação dos fatores componentes segue.

\footnotetext{
${ }^{3}$ Escola de mais alto nível do EB, a qual congrega anualmente duas turmas de oficiais, os quais serão, em primeira instância, os assessores dos comandantes em todos os níveis. A ECEME tem como missão preparar oficiais superiores para o exercício de funções de Estado-Maior, Comando, Chefia, Direção e de Assessoramento aos mais elevados escalões da Força Terrestre. Além disso, coopera com os órgãos de Direção Geral e Setorial no desenvolvimento da Doutrina Militar para o preparo e o emprego da Força Terrestre.

${ }^{4}$ Os termos Exército Brasileiro, Exército e Força Terrestre serão utilizados com o mesmo significado neste trabalho.

${ }^{5} \mathrm{O}$ processo de transformação organizacional possui diversos autores, contudo, este trabalho enfocará a abordagem de Paulo Motta.
} 
Na perspectiva estratégica, compreende-se a organização como um sistema aberto e inserido em um contexto social, econômico e político. Privilegia-se sua forma de relacionar-se com a sociedade, a recepção dos produtos e seus serviços. Nessa perspectiva, contemplam-se duas vertentes bem definidas: o relacionamento com a sociedade e o pensamento estratégico (FARREL e TERRIFF, 2002).

Na perspectiva estrutural, a organização é tratada como um sistema de autoridade e responsabilidade, pelo conjunto de normas e orientações que determinam o comportamento. Logo, para mudar uma organização há que se redistribuir formalmente a autoridade e a responsabilidade (FARREL e TERRIFF, 2002). São afetadas por essa estrutura as hierarquias, relações entre indivíduos e, consequentemente, as relações de poder.

Na perspectiva tecnológica, destacam-se elementos como a divisão do trabalho, a especialização de funções e o tipo de tecnologia empregada na produção. Para mudar uma organização, deve-se realçar e revisar a forma pela qual se utilizam os recursos materiais e intelectuais, redistribuindo funções e controle. Inovações podem ser entendidas mediante a centralização no processo e na informação (FARREL e TERRIFF, 2002).

Na perspectiva humana, a organização é compreendida como um conjunto de indivíduos e grupos, focando na relação do indivíduo com o trabalho, mediante um olhar sobre a motivação, a liderança e demais fatores psicossociais. A mudança organizacional é focada em atitudes, comportamentos e a participação dos indivíduos. As inovações, podem ser entendidas em quatro grandes áreas: movimentação entre cargos, estimativa da contribuição, retribuição e desenvolvimento individual (FARREL e TERRIFF, 2002).

A perspectiva cultural, envolve o conjunto de valores, crenças e hábitos coletivamente compartilhados, e é expressa em diversos momentos na organização como nas reuniões, na estrutura, entre outras. O processo engloba o "coletivamente compartilhado" acima do aspecto individual, focando em cada grupo social ou organização (FARREL e TERRIFF, 2002). Essa dimensão requer o cuidado de abordar aspectos relevantes, compreensíveis e aceitáveis para a coletividade, acima dos interesses individuais.

Na perspectiva política, a organização é vista como um sistema de poder em que pessoas ou grupos procuram maior influência no processo decisório. O poder é visto como um fim em si ou como um instrumento para que determinadas ideias prevaleçam sobre outras, tendo em vista que existem limitações de recursos, formação de subgrupos de poder, disputas por influência e ganhos pessoais. A mudança organizacional é vista como uma negociação interna e de solução de conflitos (FARREL e TERRIFF, 2002). Na administração pública, além da recorrência de temas, dilemas, paradoxos e a busca de novos conhecimentos para a solução de problemas práticos, vigora uma certa ingenuidade sobre a relevância da dimensão política e das condições de trabalho (MOTTA, 2013).

Mediante a diversidade de perspectivas, cabe compreender que essas não existem de forma isolada. Cada realidade propicia a predominância de uma ou outra perspectiva, que seja coerente à configuração no ambiente - conforme ressaltado por Motta -, podendo ser aplicado ao processo de transformação das Forças Armadas. Em adição, processos de mudança podem sofrer interferências de elementos diversos, direta ou indiretamente. Conflitos derivados de interesses, valores, aspectos psicológicos e obstáculos operacionais podem afetar os ciclos de vida de projetos inovadores, dependendo fortemente na capacidade política de seus líderes (DONATO, KUBO e DOMINGUES, 2013). Inclusive, para efeito de exemplo, em situações como a implantação de Sistemas de Gestão da Informação, as resistências podem predominar nas perspectivas política, humana e cultural (PAIVA e ANDRADE, 2013). 
No ambiente da gestão de organizações da Defesa Nacional e de suas organizações, o processo de transformação demanda, sobremaneira, a ruptura de alguns modelos tradicionais de administração e a introdução de uma nova cultura organizacional que permita a promoção de um ambiente adequado aos processos inovadores no setor (FRANCO-AZEVEDO, 2013). Possivelmente, a cultura seja o ponto basilar para a inserção de mudanças em tais organizações, fato esse já reconhecido no processo de transformação do Exército Chileno (GÚSMAN, SCHMITT e MORETTO NETO, 2013). De outra perspectiva, a mudança no ambiente militar pode ser considerada como um desafio adicional, dado que organizações militares, na condição de comunidades socialmente fechadas e conservadoras, são especialmente pouco inclinadas à inovar (FARRELL, 2008).

\subsection{Transformação em organizações militares voltadas para Defesa Nacional}

Na literatura tradicional sobre administração, parte-se do preceito de que a estratégia precede a configuração da estrutura (CHANDLER, 2000). Transformar uma organização militar da Defesa Nacional, portanto as Forças Armadas, significa adequar estrategicamente suas estruturas à estratégia formulada, adquirindo novas capacidades e contemplando elementos como: 1) a hipótese de guerra (ameaças convencionais); 2) ameaças novas ou não convencionais; 3) compromissos estratégicos; e 4) papel no desenvolvimento (COVARRUBIAS, 2005). Paralelamente, há a necessidade de seguir preceitos provenientes tanto de organizações públicas como peculiaridades das organizações militares.

Diferentemente da realidade de organizações civis, o contexto militar demanda do profissional uma espécie fusão entre profissão e organização, em que aspectos estritos da carreira e burocráticos estão presentes simultaneamente (CAFORIO, 2007). Tal situação exige das Forças Armadas, principalmente na América do Sul, o emprego marcado pelos pilares da destinação de seus países, das capacidades necessárias para o cumprimento se suas missões e da base constitucional que respaldam sua aplicação (COVARRUBIAS, op. cit.). Transformar as Forças Armadas em países sulamericanos significa atender a cada um destes pilares estabelecidos, conforme três concepções específicas: a adaptação, a modernização e a transformação - ressalta Covarrubias. A distinção entre cada um dos três elementos está, fundamentalmente, no grau de intervenção, nas estruturas e capacidades para o alcance das missões previstas pelas organizações.

A adaptação prevê a adequação de estruturas; a modernização prevê a otimização de estruturas e conceitos; enquanto que a transformação visa desenvolver novas capacidades ou até mesmo desempenhar novas funções. Faz-se necessário estudar e adaptar estes conceitos à realidade nacional de cada país - destaca Covarrubias (op. cit.). Transformar significa adequar estrategicamente a estrutura, adquirindo novas capacidades, mediante uma coerência entre a base legal e a sua destinação, enquanto se aborda os três pilares fundamentais neste processo, contemplando ainda, elementos como: 1) a hipótese de guerra (ameaças convencionais); 2) ameaças novas ou não convencionais; 3) compromissos estratégicos; e 4) papel no desenvolvimento, ressalta o autor. Há um complexidade e especificidade elevada envolvida no processo.

Covarrubias (op. cit.) aponta que a peculiaridade da organização militar é de que a transformação é um processo de antecipar-se às mudanças naturais, atuar proativamente, em assuntos militares e de cooperação, pela combinação de: conceitos, capacidades, indivíduos e organizações, explorando as vantagens da nação e protegendo-se contra as vulnerabilidades assimétricas. O intuito da transformação da organização militar é, de modo geral, um esforço dire- 
cionado para a melhoria do desempenho em termos de eficiência no seu emprego, notadamente a pronta resposta e a gestão de recursos (humanos, financeiros e materiais), proporcionando a execução de um ataque preventivo ou preemptivo, que se diferenciam especificamente pela representatividade da nação no cenário global e pelo grau de informação do soldado em relação à opinião pública, complementa o autor.

Em termos ilustrativos, uma Força Armada transformada atinge seu ponto máximo de intensidade mais cedo que uma força militar convencional, tornando-se mais curta e menos dispendiosa (COVARRUBIAS, op. cit.), conforme apontado na figura que segue.

Figura 1 - Quadro de emprego de uma Força Armada ${ }^{6}$

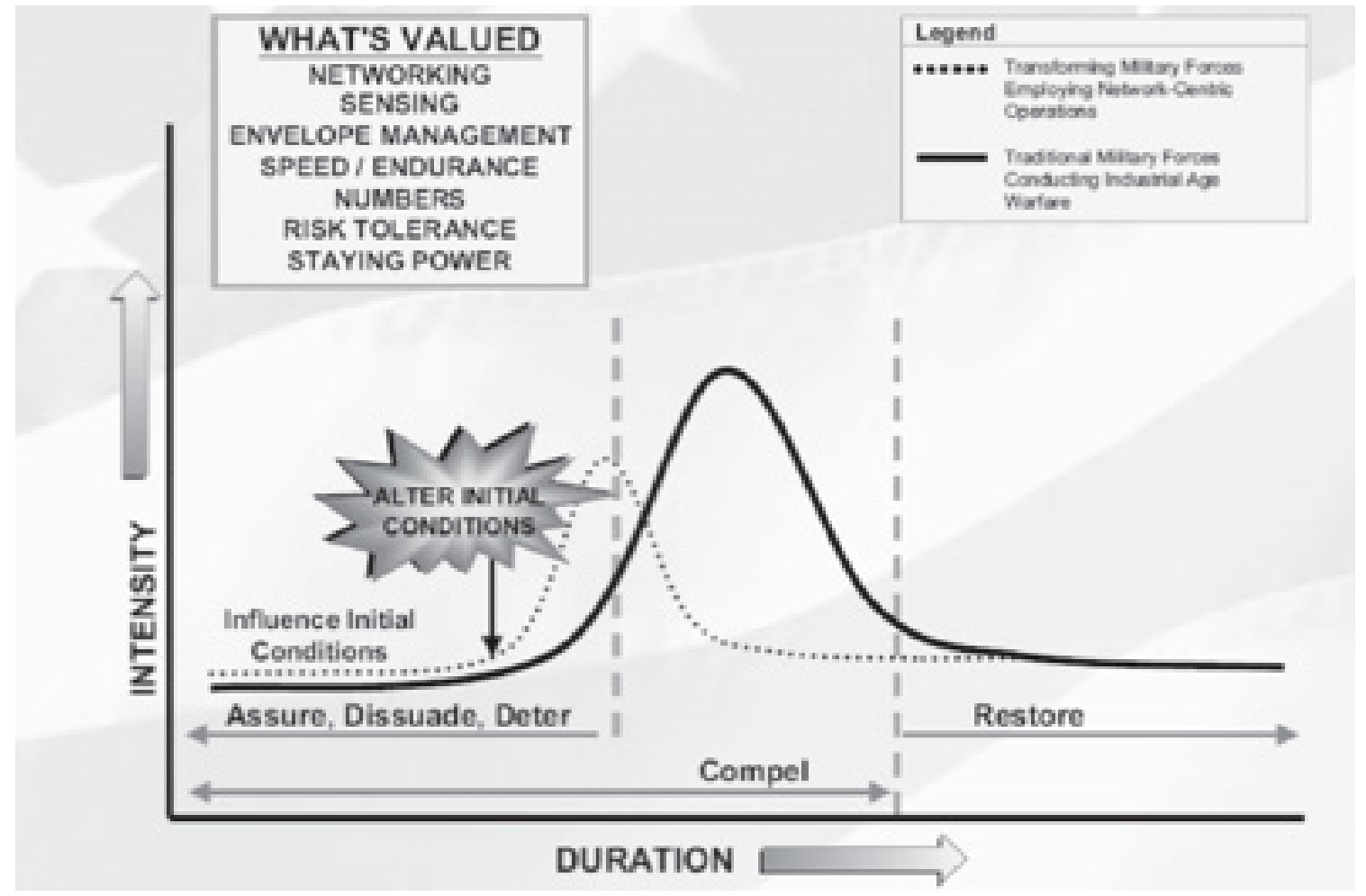

Fonte: Covarrubias, 2005

Para fazer frente ao contexto, as competências, no ambiente de organizações militares, são desenvolvidas ao longo da carreira, nas distintas escolas de formação. No âmbito da Escola de Comando e Estado-Maior do Exército, escola de mais alto nível dentro da força terrestre, há o entendimento de que competências são compostas de conhecimentos, habilidades, atitudes, valores e experiências. Desta forma, parte-se da lógica de que: 1. conhecimentos adquirem-se; 2. habilidades desenvolvem-se; 3 . atitudes resultam de motivações; 4. valores relacionam-se à

\footnotetext{
${ }^{6}$ What's valued (tradução livre) - "o que é valorizado". Networking, sensing, envelope management, speed, endurance, numbers, risk tolerance, staying power (tradução livre) - "rede de conhecimentos, detecção, gestão global, velocidade, resistência, números, risco tolerável, poder de permanência". Transforming Military Forces employing networking centric operations (tradução livre) - "transformando forças militares empregando operações centradas em redes". Tradicional Military Forces conducting industrial age warfare (tradução livre) - "forças militares tradicionais conduzindo a guerra na Era Industrial". Alter initial conditions (tradução livre) "mudar as condições iniciais". Influence initial conditions (tradução livre) - "influenciar as condições iniciais". assure, dissuade, deter, restore, compel (tradução livre) - "assegurar, dissuadir, impedir, restaurar, obrigar".
} 
defesa da pátria; 5. experiências vivenciam-se (SCHMITT, COSTA e MORETTO, 2012).

Valores e experiências são aspectos únicos decorrentes do cotidiano e fundamentais ao desempenho das competências militares. $O$ desenvolvimento de competências e conhecimentos atuais, condizentes com o momento atual e com a prática institucional tornam-se elementos básicos para a composição de uma abordagem estratégica. Todavia, constata-se que na administração pública brasileira a adoção de modelo de gestão por competências eficientemente ainda está bastante distante da realidade, especialmente em função de barreiras culturais (SILVA, MELLO e TORRES, 2013).

Exemplo da relevância do processo educacional e de desenvolvimento de competências está no processo de transformação adotado pelo Exército do Chile, que pode ser usado como uma referência na América do Sul. O esforço de transformação dessa organização resultou de um processo inicialmente centrado em uma educação com (GUSMÁN, 2013, p. 8):

[...] forte conotação cultural, aspecto este que possibilitou posteriores e sucessivas modificações em diferentes áreas, entre as quais se destaca a mudança de um paradigma territorial por um operacional, tendo um grande impacto na estrutura e na cultura organizacional da instituição. Este dado permitiu ainda demonstrar, em última análise, que o processo de transformação institucional e especialmente o cultural foram objeto de circunstâncias tanto planejadas como também não planejadas que, de qualquer forma, contribuíram para a consolidação e a continuidade, até os dias de hoje, do próprio processo, levando-se em consideração a sua condição atual de "contínuo". (GUSMÁN, 2013, p. 8)

Nesse caso, constata-se que o processo de transformação foi reflexo da conjunção de fatores em que tiveram destaque as dimensões da cultura, estratégia e educação.

\subsection{O processo de transformação do Exército Brasileiro}

Para compreender a transformação no Exército Brasileiro, é relevante analisar a sua realidade contextual e organizacional.

Em termos contextuais, dois foram os grandes marcos para a reconfiguração das forças: 1. a criação do Ministério da Defesa, no ano de 1999 - processo previamente mencionado; 2. a Estratégia Nacional de Defesa (END), no ano de 2009. O Ministério da Defesa demandou das organizações militares uma nova postura de gestão e perspectiva, sobretudo de integração entre as forças e a aproximação entre civis e militares. Subsequentemente, a Estratégia Nacional de Defesa foi um marco legislativo para o setor - tanto para organizações públicas como privadas, civis e militares -, podendo ser caracterizada como um marco no debate, que visa proporcionar uma interação dos segmentos civis e militares da sociedade (MAIA NETO, 2011). Este documento estabeleceu diretrizes e orientações para as Forças, sendo reformulada em 2013. Na visão de Vasconcellos (2011), a END representa o vínculo entre o conceito e a política de independência nacional, de um lado, e as Forças Armadas para resguardar essa independência, de outro.

Em termos organizacionais, no Exército Brasileiro, o processo de transformação tem como intenção estratégica tornar a organização, na sua totalidade, em uma instituição caracterizada pela realidade integrada de Defesa Nacional. Em consequência, de contexto e necessidade organizacional, as Forças Armadas brasileiras passaram a atuar sob uma realidade que demanda mudanças culturais em seu modus operandi, notadamente por conta de questões como a necessidade de aproximação entre civis e militares, bem como da maior interoperabilidade entre as Forças. Visando a adaptação a essa realidade, em termos de gestão, no caso do 
Exército foi estabelecido a Estratégia Braço Forte (EBF), "composta de 02 (dois) planos, 04 (quatro) programas e 824 (oitocentos e vinte e quatro) projetos, distribuídos em 129 (cento e vinte e nove) ações estratégicas" (BRASIL, 2009, p.7), a serem desdobrados em curto, médio e longo prazo (2014 - 2022 - 2030). Nele, estavam dois programas referentes à articulação:

Programa Amazônia Protegida: Abrangendo três projetos principais: Pelotões Especiais de Fronteira, o Sistema Integrado de Monitoramento de Fronteira (SISFRON) e Reestruturação das Brigadas de Selva, completando e modernizando seus sistemas operacionais.

Programa Sentinela da Pátria: destinado à reestruturação e à modernização de todas as Brigadas e estruturas dos demais Comandos Militares de Área. (Brasil, 2010)

duas partes:

Além disso, referente ao equipamento, a Estratégia Braço Forte desdobra-se em

Programa Mobilidade Estratégica, que incidirá sobre o Exército do presente, por meio do qual se pretende completar e modernizar os equipamentos e as dotações de suprimentos. As ações de curto prazo terão caráter de urgência, para que até 2014 tenhamos assegurado os níveis mínimos necessários ao adequado desenvolvimento das atividades de preparo e emprego e, com isso, restabelecido a capacidade dissuasória mínima. As aquisições desse programa deverão equilibrar a garantia da capacidade de dissuasão; as quantidades suficientes para equipar as unidades; a prioridade para produtos nacionais; e o máximo avanço tecnológico possível.

Programa Combatente Brasileiro do Futuro - COBRA - destinado a equipar o Exército do futuro. Por intermédio de projetos de Ciência e Tecnologia, desenvolverá os sistemas de armas a serem adotados a partir de 2014, dando cumprimento a um dos três chamados eixos estruturantes contidos na END: fortalecer a Indústria Nacional de Material de Defesa (Brasil, 2010).

O Estado-Maior do Exército (EME) elaborou junto com integrantes da 7ạ Subche-

fia do EME - responsável por estratégias da Força -, com a contribuição de diversas organizações militares - em especial da Escola de Comando e Estado-Maior do Exército (ECEME), o documento denominado "O Processo de Transformação do Exército (PTEx)". Seu conteúdo demonstrava que a permanência do status quo não permitiria ao Exército cumprir as demandas exigidas seja pela Estratégia Nacional de Defesa (2008), seja pela Estratégia Braço Forte, destaca Maia Neto (2011).

No Processo de Transformação do Exército, sobressai a necessidade da mudança organizacional interna, a fim de tornar viável a Estratégia Braço Forte, sendo identificadas três principais áreas de estudo: doutrina, recursos humanos e gestão. Essas áreas compõem os fatores críticos de sucesso, que são associados a outras questões como: o efetivo de aproximadamente 200.000 (duzentos mil) integrantes; a grande quantidade de organizações militares (cerca de seiscentos e cinquenta); a alta rotatividade do pessoal de carreira; e a disciplina e a hierarquia como princípios basilares da cultura organizacional (MAIA NETO, 2011), conduzindo para eleição de vetores de transformação.

Contudo, levando-se em conta a estrutura e a cultura institucionais, as ações com vista na superação de cada um deles serão conduzidas por meio de Vetores de Transformação (VT), os quais compreenderão os estudos, os diagnósticos, as concepções, os planejamentos, os processos, as ferramentas, os recursos humanos, as capacitações e os meios necessários. (Brasil, 2010) 
O Estado-Maior do Exército e os Órgãos de Direção Setoriais do Comando do Exército são os responsáveis pela condução, análise e monitoramento dos vetores de transformação, integrando-os e proporcionando os meios necessários ao seu desenvolvimento, sendo, estes, categorizados, inicialmente em sete vetores, a lembrar: Ciência e Tecnologia, Doutrina, Educação e Cultura, Gestão, Logística, Preparo e Emprego e Recursos Humanos.

O 1으 Vetor (Doutrina) busca transformar as concepções doutrinárias atuais, necessitando adequar-se aos conflitos contemporâneos, tais como: proteção do combatente, minimização de danos colaterais sobre as populações e o meio-ambiente, a opinião pública, superioridade de informações e o domínio da "consciência situacional" (Brasil, 2010). Para tanto, no intuito, de retirar o Exército da era industrial para era da informação, assentada em ferramentas da tecnologia da informação (TI), considera-se necessário reestruturar o Sistema de Doutrina do EB, modernizando-o e dando novas funcionalidades, como: informações doutrinárias, lições aprendidas, modelagem, simulação, estudo da guerra, e processamento, formulação, experimentação, validação e difusão. Tais elementos passam a ser considerados os motores da transformação, sendo responsável pela cultura institucional, amparados em cenários de longo prazo, as hipóteses de emprego, a partir de um sistema de prospecção estratégica, doutrinária e de C\&T (BRASIL, 2010).

O 2 Vetor, Preparo e Emprego, busca transformar as estratégias de preparo e emprego, as quais, ainda, estão baseadas na conscrição e realizada ao longo do ano de instrução. Tais fatos dificultam a Força Terrestre de acompanhar as responsabilidades do País assumidas no contexto internacional, da mesma forma, deixam de atender às necessidades decorrentes dos Planos Operacionais relativos às Hipóteses de Emprego (BRASIL, 2010).

O 3 Vetor, Educação e Cultura, busca transformar estas áreas. Visualiza-se que a intenção de superar algumas deficiências, como a baixa eficiência da atividade de capacitação e a precária mentalidade de inovação dos quadros. Ressalta-se ainda a necessidade de entender a diferença entre Educação e Capacitação, sendo a primeira "destinada a produzir efeitos permanentes sobre os recursos humanos (RH)" e a segunda "destinada ao desenvolvimento de habilidades específicas, com ênfase na realização de tarefas que exijam algum tipo de especialização", mostrando que o processo de transformação busca uma maior efetividade dos seus quadros, após a realização de seus cursos (BRASIL, 2010).

$\mathrm{O}$ 4ㅇ Vetor, Gestão dos Recursos Humanos, visa transformar a gestão dos RH, a fim de superar algumas deficiências, focando no ajuste da composição dos efetivos e na gestão de pessoal. No ajuste na composição dos efetivos, é necessário pensar em uma adequação dos efetivos que cumpra a concepção estratégica vigente, focando nas atividades-fim. A gestão de competências passa a ser um ponto vital, a fim de que o EB conte com Recursos Humanos mais capacitados e na quantidade necessária, sendo fundamental para o êxito das atividades de C\&T, além das novas demandas de especialização decorrente do processo de transformação.

O 5o Vetor, Gestão Corrente e Estratégia, busca transformar a gestão atual do EB e a estratégia vigente, a fim de melhorar a concepção da Força, adotando medidas estruturais e sistêmicas para a Força. Dentre as medidas estruturais destacam-se a redução dos efetivos empregados em atividades que não sejam as operacionais e a modernização dos métodos de gestão administrativas; e nas medidas sistêmicas destacam-se a necessidade reestudo da estrutura organizacional da alta Administração do EB e focar nos métodos de gestão por projetos e processos, com ênfase na execução.

O 6o Vetor, Ciência e Tecnologia (C\&T) e Modernização do material, busca transformar a área de C\&T e a consequente modernização dos materiais de emprego militar (MEM), tendo 
em vista o extenso tempo de vida dos MEM. Esta transformação é descrita como imperiosa e urgente, a fim de proporcionar a Força Terrestre cumprir as novas capacidades elencadas na END, monitoramento/vigilância, mobilidade e presença, além de permitir o desenvolvimento da capacidade de inovação de seus quadros, principalmente, dos mais novos que adentram ao EB, tais como os níveis mais alto de Praças (como os 3 ㅇ Sargentos) e Aspirantes-a-oficial.

0 70 Vetor, Logística, busca transformar a área logística da Força Terrestre, a qual já foi referência no passado. Atualmente, essa dimensão incorpora alguns conceitos das empresas civis como forma de aperfeiçoar a sua gestão. Neste contexto, o EB vem melhorando sua gestão administrativa da logística, criando órgãos gestores de suma importância para a Força, como o Departamento Logístico (D Log). A execução da atividade de logística busca a concentração das funções logísticas de transporte, suprimento e manutenção de material em um único órgão de Direção Setorial, além de outras mudanças estruturais nas Regiões Militares, divisão mais ampla da estrutura da força e organizações militares, elementos estruturantes das regiões componentes da força.

Estes vetores da Estratégia Braço Forte visam transformar o Exército Brasileiro em uma Força apta a combater com as ameaças do século XXI, estando coerente com a Política Nacional de Defesa e com a Estratégia Nacional de Defesa. De modo geral, em termos de gestão, inicialmente, são constatadas inovações como a implantação de mapeamento de processos, avaliação diagnósticas da gestão, delimitação de fatores de custos e adoção de estruturas funcionais, vislumbrando dentre outros a adequação com a administração pública gerencial (CRUZ NETO, 2013).

A mudança parte, portanto, do princípio de que novas configurações organizacionais são derivadas dos processos institucionais, sendo difícil manter uma coerência única, pois dependem de diversos fatores como cultura, valores, competência, sociedade e legalidade (MOTTA, op. Cit.). Tamanhas são as especificidades que, no ambiente militar, existem três atributos que qualificam a profissão, sendo eles a especialidade, a responsabilidade e o corporativismo. A especialidade é adquirida ao longo da educação e experiência. A responsabilidade é adquirida em conjunto com a sociedade. O corporativismo deriva da consciência do grupo profissional (HUNTINGTON, 1996). Contudo, processos desse vulto estão passíveis de agir como fator de desestruturação das organizações, fazendo com que elas busquem, incessantemente, meios para gerenciar uma gama enorme de informações, procurando analisá-las e transformá-las em conhecimento (DRUCKER, 2002). A diversidade de informações e conflitos derivados das mudanças são processos emergentes a serem gerenciados, durante o processo de adaptação, afim de obter reais melhorias nos processos.

Mesmo sabendo da existência da interdependência entre competência e cultura, essas podem ser contraditórias ou complementares (FLEURY, 2009). Competências e cultura influenciam na organização político-administrativa da Força Terrestre - o Exército Brasileiro -, mesmo dependendo de variáveis independentes da vontade da mesma, como as geográficas, demográficas, econômicas, históricas e culturais (VIEIRA, 2012). Em adição, o modelo organizacional burocrático característico das organizações públicas, por consequência também das Forças Armadas, apresenta características e críticas, dentre as quais estão o impacto da prescrição estrita de tarefas sobre a motivação dos empregados, resistência às mudanças e desvirtuamento de objetivos.

Nesse sentido, ressalta-se a importância de entender, também, o termo governança pública (GP), que na linguagem empresarial significa um conjunto de princípios básicos para aumentar a efetividade de controle; enquanto na administração pública caracteriza-se por um modelo horizontal de relação entre atores públicos e privados no processo de elaboração de políticas pú- 
blicas (SECCHI, 2009). Ou seja, o ponto de distinção está na amplitude de participação e controle, com vistas ao alcance de resultados.

[...] qualquer verificação empírica sobre reformas da administração pública deve estar atenta aos aspectos incrementais de mudança organizacional. Ao invés de falar em ascensão, predomínio e declínio de modelos organizacionais, talvez seja mais frutífero falar em um processo cumulativo de mudanças nas práticas e valores (SECCHI, 2009, pag. 365).

O entendimento organizacional parte da necessidade de alinhamento comportamental dos indivíduos que compõem essa instituição, ação essa realizada a partir dos quadros de Estado-Maior, de forma análoga ao meio civil, níveis de assessoramento e gerência, de modo que compreender a percepção que os quadros, reconhecidos como formadores de opinião, têm acerca do processo torna-se relevante para a sua condução.

\section{MÉTODO DE PESQUISA}

O presente trabalho segue uma abordagem explicativa e descritiva, pois busca explicar as questões do processo de transformação do Exército, descrevendo seus pontos considerados centrais, quais sejam os vetores do denominado Processo de Transformação do Exército. Para a sua consecução, foi realizada uma pesquisa de campo, por meio da aplicação de um questionário estruturado com 6 (seis) questões centrais, fechadas, com desdobramentos relacionados com o processo. As perguntas contemplaram, em sua primeira parte, elementos relacionados com o tema da transformação do Exército. O questionamento eleito foi do tipo Survey, o qual é estruturado em um método de pesquisa de levantamento de opinião pública - com cinco níveis de resposta na escala Likert - visando buscar a opinião dos respondentes, especificando o seu nível de concordância com uma afirmação. Na segunda parte do questionário, demandou-se dos respondentes uma avaliação relacionada à percepção sobre a condução do processo de transformação do Exército Brasileiro. Nessa etapa, os respondentes, tiveram a opção de elencar, dentre os quesitos iniciais, quais eram percebidos como de maior grau de dificuldade, destacando-se os itens principais.

Como parâmetro para os questionamentos apresentados na pesquisa, foram consideradas as seis variáveis eleitas para definir o processo de transformação (MOTTA, op. cit.), sendo adotadas as respectivas abreviações no corpo do texto: estratégica (est), estrutural (etr), tecnológica (tec), humana (hum), cultural (cul) e política (pol). Em adição, foi incluída questão focada na percepção dos respondentes - oficiais do EB - sobre a condução do processo de transformação. Consequentemente, foi estabelecida, por meio da regressão logística, a relação entre as seis variáveis (estratégica, estrutural, tecnológica, humana, cultural e política) com a percepção positiva ou negativa acerca da condução do processo de transformação corrente.

As hipóteses da investigação foram as seguintes:

- H1: a teoria de transformação organizacional pode ser aplicada ao EB.

- H2: existe uma relação entre os fatores de transformação organizacional e o processo de transformação do EB. 
O Universo da pesquisa foi composto por oficiais militares do corpo discente da Escola de Comando e Estado-Maior (ECEME) do Curso de Altos Estudos Militares (CAEM) ${ }^{7}$, englobando os alunos do 1 ㅇan ano, com 130 militares, e do 2 ㅇ ano, com 110 militares. A amostra foi selecionada seguindo o método de amostragem probabilística, garantindo uma margem de erro de cerca de $5 \%$ e um nível de significância de cerca de $95 \%$ (HAIR et al., 2009). A amostra da pesquisa foi de 148 (cento e quarenta e oito) respondentes, sendo 43 do segundo ano do CAEM e 105 do primeiro ano. Os questionários foram aplicados em um único momento, no mês de novembro de 2013 por meio de um corte-transversal.

O tratamento dos dados seguiu o método quantitativo, usando o software SPSS 16.0 como ferramenta de processamento, de forma a auxiliar uma Análise Fatorial e uma Regressão Logística Binária. O processamento das pesquisas foi realizado com o software SPSS 16.0, sendo analisados 148 (cento e quarenta e oito) questionários.

As limitações do estudo estão na seleção da amostra, já que somente militares alunos da ECEME integraram a amostra, o que pode prejudicar as generalizações decorrentes. Torna-se interessante a aplicação deste questionário em outros institutos de ensino do EB e organizações que o compõem, a fim de ampliar as referidas generalizações elencadas no presente trabalho.

\section{ANÁLISE DOS RESULTADOS}

\subsection{Apresentação dos resultados}

O primeiro passo para a análise dos dados foi a verificação do Alfa de Cronbach, uma espécie de medida diagnóstica do coeficiente de confiabilidade que avalia a consistência da escala inteira, sendo o mais usado para tal tarefa. O intuito da verificação estava na confirmação acerca da do potencial das variáveis levantadas para a explicação do construto "transformação organizacional" do EB. Conforme orienta HAIR et. al. (2005; 2009), valores desejáveis são os acima de 0,7 sendo que, os abaixo de 0,5 , invalidam a pesquisa. $O$ valor encontrado foi de 0,862 e, portanto, acima do recomendado, confirmando a aceitação das variáveis eleitas.

A validade da referida escala foi buscada, de forma a medir realmente desejado, buscando a validação interna por meio da equidade na aplicação do instrumento de pesquisa e a validação externa por meio da validade de conteúdo, também chamada de face validity, em que um especialista confirma a qualidade da pesquisa. Após a verificação da confiabilidade e da validade do construto, foi realizada a análise fatorial, surgindo apenas um fator que englobou todas as variáveis propostas, confirmando, estatisticamente, a hipótese H1 da investigação. Desta forma, foi possível agrupá-las em um único fator, denominado "transformação organizacional" conforme demostrado na Tabela 1.

\footnotetext{
${ }^{7}$ Curso com duração de dois anos, o qual habilita o oficial a compor o Quadro de Estado-Maior do Exército Brasileiro.
} 
Fator

Variáveis

1

\begin{tabular}{|c|c|}
\hline est & 0,722 \\
\hline etr & 0,801 \\
\hline tec & 0,662 \\
\hline hum & 0,814 \\
\hline cul & 0,815 \\
\hline pol & 0,718 \\
\hline
\end{tabular}

Fonte: OS AUTORES, 2014.

Da análise da tabela 01, no construto (transformação organizacional) destacam-se três variáveis na sua relevância e influência, quais sejam: cultural (cul), humana (hum) e a estrutural (etr) - com valores de $0,815,0,814$ e 0,801 , respectivamente. Analisada a percepção dos entrevistados com relação a condução do processo de transformação do EB, de um total de 148 (cento e quarenta e oito) respostas válidas, foram obtidas 87 (oitenta e sete) respostas positivas, enquanto 61 (sessenta e um) responderam negativamente.

Tabela 2 - Correlações de Variáveis

\begin{tabular}{l|l|lllllll}
\hline & & est & etr & tec & hum & cul & Pol \\
\hline Correlation & est & 1,000 &, 535 &, 429 &, 464 &, 484 &, 388 \\
& etr &, 535 & 1,000 &, 486 &, 523 &, 586 &, 482 \\
& tec &, 429 &, 486 & 1,000 &, 426 &, 401 &, 341 \\
& hum & cul &, 464 &, 523 &, 426 & 1,000 &, 675 &, 559 \\
& pol &, 384 &, 586 &, 401 &, 675 & 1,000 &, 500 \\
& & &, 482 &, 341 &, 559 &, 500 & 1,000 \\
\hline
\end{tabular}

Fonte: OS AUTORES, 2014. 
Além disso, pela análise da tabela 02, foi possível estabelecer correlações entre as variáveis do construto transformação organizacional, sendo considerado aceitável quando superior a 0,500. Constatou-se que conforme o respondente escolhia a variável estratégia, essa aumentaria em $53,5 \%$ a probabilidade de eleger a variável estrutural concomitantemente. Em adição, observou-se que, conforme o respondente apontasse a variável estrutural, aumentaria em $53,5 \%$ a chance de destacar a variável estratégia, crescendo em $52,3 \%$ a chance de escolha da variável humana e em $58,6 \%$ a possibilidade de escolha da variável cultural. Tais achados destacaram e confirmaram: 1 . a forte relação entre estratégia e estrutura; 2 . a influência de estratégia e estrutura nas variáveis humana e cultural.

Ainda na tabela 02, conforme o respondente apontava a variável humana, aumenta em $52,3 \%$ a chance de escolha a variável estrutural, elevando em $67,5 \%$ a chance de eleição da variável cultural e em $55,9 \%$ a variável política. Em adição, verificou-se que conforme o respondente tendesse a escolher a variável cultural, aumentaria em $58,6 \%$ a chance de escolher a variável estrutural e em $67,5 \%$ a variável humana. Por fim, caso houvesse a escolha da variável política, elevaria em $55,9 \%$ o potencial de eleição da variável humana. Tais resultados ressaltaram a relação intrínseca e de influência entre as variáveis humana, com as dimensões cultural e política.

Na regressão logística aplicada, buscou-se avaliar - por intermédio do Omnibus Tests of Model Coefficients - confirmar a percepção acerca da percepção positiva dos estudados sobre a condução do processo de transformação do EB. Neste teste, a hipótese seria rejeitada caso sua significância fosse inferior a 0,001 . Na pesquisa em tela, a significância encontrada foi de 0,000 , mesmo assim o teste do "block 1 " foi capaz de prever $70,9 \%$ das vezes, sendo superior ao "block 0". Portanto, as variáveis utilizadas aumentam a capacidade de prever que a priorização da opinião de um respondente seja de que a transformação do EB esteja sendo bem conduzida - na perspectiva da amostra estudada.

Em adição, foi realizado o teste de Hosmer-Lemeshow, visando verificar o ajustamento entre modelo e dados. $O$ valor apurado foi de 0,543 , indicando bom ajustamento à pesquisa realizada - sendo valores acima de 0,05 referência para a significância estatística positiva.

Tabela 3 - Variáveis Logística

\begin{tabular}{|c|c|c|c|c|c|c|c|c|}
\hline & \multirow{2}{*}{ B } & \multirow{2}{*}{ S.E. } & \multirow{2}{*}{ Wald } & \multirow{2}{*}{ Df } & \multirow{2}{*}{ Sig } & \multirow{2}{*}{$\operatorname{Exp}(B)$} & \multicolumn{2}{|c|}{$\begin{array}{l}95,0 \% \text { C. I. for EXP } \\
\text { (B) }\end{array}$} \\
\hline & & & & & & & Lower & Upper \\
\hline est & 0,508 & 0,240 & 4,476 & 1 & 0,034 & 1,661 & 1,038 & 2,659 \\
\hline etr & 0,295 & 0,305 & 0,935 & 1 & 0,334 & 1,343 & 0,739 & 2,442 \\
\hline tec & 0,494 & 0,239 & 4,291 & 1 & 0,038 & 1,639 & 1,027 & 2,617 \\
\hline hum & 0,358 & 0,256 & 1,961 & 1 & 0,161 & 1,430 & 0,867 & 2,361 \\
\hline cul & $-0,186$ & 0,267 & 0,482 & 1 & 0,488 & 0,831 & 0,492 & 1,403 \\
\hline pol & $-0,081$ & 0,216 & 0,140 & 1 & 0,709 & 0,922 & 0,604 & 1,409 \\
\hline Constant & $-4,705$ & 1,139 & 17,076 & 1 & 0,000 & 0,009 & & \\
\hline
\end{tabular}

Fonte: OS AUTORES, 2014. 
A partir da análise da tabela 03, verificou-se a relação da percepção acerca do processo de transformação - positiva ou negativa -, em detrimento às perspectivas de análise. Indivíduos que perceberam condução do processo de transformação do EB de forma positiva, demoro geral elegeram como prioritárias as perspectivas estratégica (est) $(0,508)$, tecnológica (tec) $(0,494)$ e humana (hum) $(0,358)$. Verificou-se ainda que os indivíduos que priorizaram as dimensões cultural (cul) $(-0,186)$ e política (pol) $(-0,081)$ tenderam a perceber a condução do processo negativamente.

Cabe destacar q u, o modelo obtido foi capaz de prever corretamente $70,9 \%$ das respostas. Em termos totais, de 148 (cento e quarenta e oito) respostas válidas, o modelo apresentou acerto 87 (oitenta e sete) vezes. Por esse motivo, pode-se dizer que o modelo adotado teve boa capacidade de previsão satisfatória. Tal achado confirmou a Hipótese $\mathrm{H} 2$ do estudo, de que existe uma relação entre os fatores de transformação organizacional e o processo de transformação do EB.

Por fim, foi estabelecida uma descrição estatística, com a finalidade de verificar os valores máximos e mínimos, a média e o desvio-padrão sobre o processo de transformação do EB, conforme tabela 04. A estatística descritiva demonstrou que não há consenso acerca da transformação organizacional em nenhum dos quesitos. Há, entretanto, tendência para a concordância, pois os valores da média são superiores a 3. Pode-se afirmar que os respondentes, prioritariamente, acreditam que as perspectivas eleitas, são relevantes para explicar a transformação organizacional do Exército Brasileiro.

Tabela 4 - Descrição Estatística

\begin{tabular}{cccccccccc}
\hline & $\mathrm{N}$ & Range & $\begin{array}{c}\text { Mini- } \\
\text { mum }\end{array}$ & $\begin{array}{c}\text { Maxi- } \\
\text { mum }\end{array}$ & \multicolumn{2}{c}{ Mean } & $\begin{array}{c}\text { Std. Devi- } \\
\text { ation }\end{array}$ & Variance \\
\cline { 6 - 8 } & & $\begin{array}{c}\text { Statis- } \\
\text { tic }\end{array}$ & $\begin{array}{c}\text { Statis- } \\
\text { tic }\end{array}$ & Statistic & Statistic & $\begin{array}{c}\text { Statis- } \\
\text { tic }\end{array}$ & $\begin{array}{c}\text { Std. } \\
\text { Error }\end{array}$ & Statistic & Statistic \\
\hline est & 148 & 4 & 1 & 5 & 3,39 & 0,078 & 0,944 & 0,891 \\
etr & 148 & 4 & 1 & 5 & 3,49 & 0,071 & 0,861 & 0,741 \\
tec & 148 & 4 & 1 & 5 & 3,51 & 0,079 & 0,958 & 0,918 \\
hum & 148 & 4 & 1 & 5 & 3,32 & 0,088 & 1,069 & 1,143 \\
cul & 148 & 4 & 1 & 5 & 3,31 & 0,082 & 1,002 & 1,005 \\
pol & 148 & 4 & 1 & 5 & 3,23 & 0,085 & 1,037 & 1,076 \\
$\begin{array}{c}\text { Valid N } \\
\text { (listwise) }\end{array}$ & 148 & & & & & & & \\
\hline
\end{tabular}

Fonte: OS AUTORES, 2014. 


\subsection{Discussão dos resultados}

Constatou-se que os sete vetores de transformação - Ciência e Tecnologia, Doutrina, Educação e Cultura, Gestão, Logística, Preparo e Emprego e Recursos Humanos - possuem relação com as seis perspectivas eleitas, quais sejam: estratégica, estrutural, tecnológica, humana, cultural e política.

Realizada a análise fatorial, destacaram-se as seguintes perspectivas como de maior destaque: a cultural, a humana e a estrutural. Tal resultado indica que os respondentes identificam nestes três fatores os aspectos principais, que influenciam no processo de transformação organizacional. Esse aspecto ficou evidenciado na tabela de correlações, em que a perspectiva cultural possui um alto índice de correlação com as perspectivas humana e estrutural, destacando a importância do vetor Educação e Cultura.

Importante destacar que as mesmas dimensões foram as que demonstraram maior atenção quando na realização de esforços adicionais na condução de processo similar no Exército Chileno (GUSMÁN, op. cit.). O mesmo vale para o caso do Exército Norteamericano, em quefoiobservado que enquanto conhecimentos individuais de liderança são fatores relevantes na transformação organizacional, atores como agentes de mudança e consumidores influenciam sobremaneira na criação de nova visão e plano estratégico para o alcance da eficiência operacional (KOHNKE e GONDA, 2013).

Tais resultados podem ser explicados pelo fato de que, em processos de transformação, faz-se necessário o trabalho de mudança comportamental, no sentido de alterar processos cognitivos individuais e paradigmas organizacionais (PORRAS e SILVERS, 1991). O esforço influencia na consciência acerca do processo, tornando-o mais visível para os membros da organização e, em perspectiva mais ampla, permite compreender como e quando iniciar as mudanças que afetam estratégia, estrutura e, consequentemente, a mudança. Ademais, cabe destacar que: 1. organizações que ambicionam a mudança devem conhecer traços da cultura que podem impor restrições, bem aqueles que fortalecem o processo de mudança (MOTTA e CALDAS, 2009); 2. a relação entre cultura e o fator humano, ao passo que essa é elemento central na compreensão da forma com que indivíduos interpretam a realidade e dão sentido ao que ocorre ao seu redor (SCHEIN, 2009); 3. o fato de que a estratégia deve preceder a definição da estrutura, conforme apontado por Chandler (op. cit).

Nesse sentido, analisando a contrapartida entre teoria e prática, com relação à dimensão cultural, observa-se que a organização estudada - o EB - tem desenvolvido distintas ações, dentre as quais destacam-se a premiação por inovações aprovadas e por textos sobre assuntos profissionais publicados; ênfase no ensino de idiomas; estímulo à leitura de publicações modernas sobre assuntos profissionais, nacionais e internacionais; maior convivência com militares de outras Forças, com civis e com estrangeiros; viagens de estudos a países mais desenvolvidos; e cursos de mestrado e doutorado em instituições civis.

Tais iniciativas corroboram o fato da necessidade de focar na identidade cultural da organização, sem provocar danos ao sentido de identidade organizacional, preservando sua cultura e favorecendo sua difusão cultural (MOTTA, op. cit.). Da mesma forma, responde à demanda de que para desenvolver competências para o emprego contemporâneo é necessário pensar numa mudança cultural que os adapte às demandas requeridas na atualidade (COSTA, 2012; 2013).

A perspectiva humana - também apontada como fator de destaque - pode ser explicada, especialmente, pelo fato de que gestores públicos têm por finalidade organizar, motivar e orientar ações de outras pessoas para criação e consecução de objetivos que justifiquem uso da 
autoridade pública (LYNN, 2010). Em adição, mudanças se tornam perenes quando há alteração comportamental dos indivíduos (MOTTA, op. cit.).

Assim, a prática institucional tem focado esforços para a implementação de medidas, entre as quais destacam-se: a valorização e aumento do efetivo de temporários e de estagiários; a terceirização de atividades administrativas; e a racionalização administrativa das OM operacionais. Essas ações corroboram o fato de que para mudar uma organização, deve-se: alterar atitudes, comportamentos e a forma de participação dos indivíduos; e proporcionar satisfação e harmonia ao ambiente de trabalho, tanto como fatores de realização e progresso pessoais como causadores de eficiência - conforme destacado por Motta.

No que se refere à perspectiva estrutural, nota-se que o EB vem implementando medidas, podendo-se citar: a valorização e aumento da quantidade de pessoal da reserva remunerada contratado; o emprego de civis, em um sistema que englobe capacitação e a elaboração de um plano de carreira; a administração por processos; e a descentralização de atribuições e de responsabilidades funcionais, podendo complementarmente transformar cargos de oficiais em cargos de praças. Essas ações novamente reforçam a relevância de que uma inovação tenha características, dentre as quais: estabelecer uma lógica coerente com a hierarquia da autoridade; distribuir poder compatíveis com o grau de responsabilidade; departamentalizar o máximo possível por objetivos ou áreas geográficas; desenhar a estrutura com base em projetos ou sistemas; e conceder autoridade sobre meios administrativos aos responsáveis sobre as atividades-fim.

Contudo, na análise logística realizada, os resultados permitiram uma visão sobre os fatores que mais afetam a percepção sobre a boa condução do processo de transformação em curso no EB. Os resultados encontrados demonstraram que para esta boa condução do processo se destacam as perspectivas estratégica, a tecnológica e a humana. Corrobora-se então que as bases da mudança na organização militar são a tecnologia, cultura e política, reforçando a importância dos vetores Doutrina, Ciência e Tecnologia e Recursos Humanos (FARREL e TERRIFF, 2002)

É importante ressaltar a relação obtida entre as perspectivas fatores cultural e política, que apontam declínio na percepção da boa condução do processo de transformação do EB. Em outros termos, mesmo diante das contribuições das perspectivas cultural - na identidade da organização - e a política - para um eficaz sistema de poder e influências em processos decisórios - geram, por sua vez, uma percepção negativa nos respondentes acerca da boa condução do processo almejado. Ainda que a perspectiva cultural seja de grande relevância - conforme destacado na análise fatorial -, a mesma - quando destacada na regressão logística -, favorece a uma percepção deficiente da boa condução do processo de transformação. Contrariamente, com a perspectiva estratégica ocorre o efeito distinto ao demonstrar ser fundamental para uma boa percepção do processo de transformação do EB. 


\section{CONSIDERAÇÕES FINAIS PARA A GESTÃO ORGANIZA- CIONAL}

O estudo realizado permitiu avaliar a percepção de formadores de opinião na instituição estudada, quais sejam alunos da ECEME - no momento do estudo - e hoje oficiais do Quadro de Estado-Maior. Com isso, conclui-se que as perspectivas da transformação organizacional eleitas indicaram que as percepções dos respondentes são significativas para explicar e justificar o processo em curso na organização estudada. A percepção existente indica um caminho neste complexo e relevante processo para a Força Terrestre, tendo como destaque a relevância das perspectivas cultural, humana e estrutural.

Há uma relação forte entre a percepção positiva sobre a condução do processo de transformação, com o senso de relevância das perspectivas estratégica, tecnológica e humana - fato esse, característico, em certo ponto, de organizações militares, conforme comentado anteriormente. Sinaliza-se, a relevância de que gestores direcionem esforços de comunicação e melhoria de processos nesta direção, visando ampliar o potencial de percepção positiva por parte da população estudada.

A relação existente entre a percepção negativa sobre o processo de transformação corrente e o entendimento de relevância das perspectivas cultural e política, demanda atenção. Ressalta-se a necessidade de observância e foco nestas duas perspectivas, a fim de reverter o eventual quadro indesejado e maximizar o potencial dos esforços realizados. Com tal postura, evita-se um processo de inovações no setor de Defesa dentro de um ambiente adequado, sem uma ruptura com o modelo tradicional de administração (FRANCO-AZEVEDO, 2013).

Por fim, as perspectivas cultural e política, da instituição estudada, merecem destaque por intermédio de esforços alocados no Processo de Transformação e, especificamente, por intermédio da Estratégia Braço Forte. Acredita-se que a promoção de ações que estimulem uma mudança no sentido positivo da percepção dos respondentes, de modo efetivo, demonstraria potencial de contribuição aos esforços realizados. A afirmação é ressaltada, tendo em vista a aceitação das demais perspectivas.

Este trabalho advoga a necessidade da compreensão da abordagem utilizada, como forma de amplificar a comunicação e imagem do processo de transformação na organização estudada - o Exército Brasileiro. Cabe ainda destacar o papel construção de lideranças, atuais e futuras, no interior da organização, a fim de que se alcance níveis elevados de desempenho, que o processo se torne sustentável e que aorganização alcance objetivo superior de adequação às necessidades de Defesa Nacional. 


\section{BIBLIOGRAFIA}

BRASIL. Exército. Estratégia braço forte. Brasília, 2009.

Exército. O processo de transformação do Exército. 3ạ Ed. Brasília, 2010.

Ministério da Defesa. Estratégia Nacional de Defesa. 2a Ed. Brasília, 2008.

Ministério da Defesa. Estratégia Nacional de Defesa. Brasília, 2013.

Ministério da Defesa. Política Nacional de Defesa. 2a Ed. Brasília, 2005.

Ministério da Defesa. Política Nacional de Defesa. Brasília, 2013.

CAFORIO, G. Trends and evolution in the military profession. En: Social Sciences and the Military: An interdisciplinary overview. London: Routeledge, 2007.

CHANDLER, A. D. Strategy and structure: chapters in the history of the american industrial enterprise. 2a Ed. Cambridge: MIT Press, 2000.

COSTA, R. P. The revolution in military affairs in the scope of military education. In: Dimitar Minchev; Jordan Baev; Kostadin Grozev. (Org.) Technology and Warfare. 1ed.Sofia: Urch Alma/ Sofia University Press, 2013, v. 1, p. 323-335.

. The potential of research to improve military education and serve the public good, In: American Educational Research Association 2012, Vancouver, Canada. Disponível em: <www. aera.net/Membership/MyAERA/tabid/11072/Default.aspx>.

COVARRUBIAS, J. G. A transformação da Defesa nos EUA e sua aplicação na América Latina. USA: Military Review, 2005, Ed. maio-junho.

CRUZ NETO, Arlindo José da. Redução dos encargos administrativos nas Organizações Militares 
Operacionais do Exército Brasileiro. Dissertação (Mestrado) - Escola de Comando e Estado-Maior do Exército, Rio de Janeiro, 2013.

DONATO, J. V.; KUBO, E. K. M.; DOMINGUES, C. R. conflito e obstáculos operacionais em gestão de projetos inovadores: um estudo empírico. Revista de Administração UFSM, v. 6, n. 4, p. 740-759, dez 2013.

DRUCKER, P. F. O melhor de Peter Drucker: obra completa. São Paulo: Nobel, 2002.

FARREL, T. The dynamics of British military transformation. International Affairs, v. 84, n. 4, p. 777-807, 2008.

FARREL, T.; TERRIFF, T. (orgs.) The sources of military change: culture, polytics, technology. Lynne Rienner Publishers: Boulder, 2002.

FLEURY, M. T. L. Organizational culture and the renewal of competences, en: Brazilian Administration Review, vol. 6, no. 1, 2009.

FRANCO-AZEVEDO, Carlos Eduardo. Gestão de Defesa: o sistema de inovação no segmento de não-guerra / Carlos Eduardo Franco Azevedo - 2013. 423 f. Tese (doutorado) - Escola Brasileira de Administração Pública e de Empresas, Centro de Formação Acadêmica e Pesquisa.

GUSMÁN, J. J. C. Transformação de um Exército. A cultura na transformação do Exército Chileno. Dissertação (Mestrado) - Escola de Comando e Estado-Maior do Exército, Rio de Janeiro, 2013.

GUSMÁN, J. J. C.; SCHMITT, V. G. H; MORETTO NETO, L. Una discusión de transformación: perspectivas para la transformación militar desde la cultura organizacional. Coleção Meira Mattos - Revista das Ciências Militares, v. 8, p. 105-115, 2014.

HAIR, Jr. J. F.; ANDERSON, R. E.; TATHAN, R. L.; BLACK, W. C. Análise multivariada de dados. 6. ed. Porto Alegre: Bookman, 2009.

Análise multivariada de dados. 5. ed. Porto Alegre: Bookman, 2005. 
HITT, M. A.; IRELAND, R.D.; HOSKISSON R. E. Administração Estratégica. Ed. São Paulo: Thomson, 2002.

HUNTINGTON, S. O soldado e o Estado: teoria e política das relações entre civis e militares. Rio de Janeiro, Biblioteca do Exército: 1996.

KALDOR, M. Elaborating the new war thesis, in Isabelle Duyvesteyn and Jan Angstrom, eds., Rethinking the Nature of War. New York: Frank Cass, 2005. p. 221.

KOHNKE, A.; GONDA, T. creating a collaborative virtual command center among four separate organizations in the United States Army: an exploratory case study. Organization Development Journal, v. 31, n. 4, p75-92.

LYNN Jr., L. E. Gestão pública. In: PETERS, B. G; PIERRE, J (ed.) Administração Pública: coletânea. Brasília: ENAP, 2010. p. 33-52.

MATHIAS, S. K. Ameaças às democracias da América Latina. In Eliézer Rizzo de Oliveira (Org.). Segurança e Defesa Nacional: da competição à cooperação regional. São Paulo: Fundação Memorial da América Latina, 2007. 288 p.

MINTZBERG, H. et al. O Processo de estratégia. 4. Ed. Porto Alegre: Bookman, 2006.

.AHLSTRAND, B.; LAMPEL, J. Safári de estratégia. Porto Alegre: Bookman, 2000.

MOTTA, P. R. M.. Transformação organizacional: a teoria e a prática de inovar. Rio de Janeiro: Qualitymark, 2001.

. Cultura organizacional e cultura brasileira. São Paulo: Atlas, 2009.

. O estado da arte da gestão pública. Sao Paulo: RAE, Jan-fev, v. 53, n. 1, 2013.

MAIA NETO, J. O processo de transformação do Exército Brasileiro: um estudo sobre os reflexos da era do conhecimento. Coleção Meira Mattos/ Revista das Ciências Militares, n. 24, p. 1-10,2011. 
PAIVA, D. S.; ANDRADE, J. C. S. Resistências à mudança organizacional: Análise do Processo de Implantação do Sistema de Gestão Integrada no SENAI-BA. Revista de Administração UFSM, v. 6, n. 3, p. 614-632, set 2013.

PORRAS, J.I.; SILVERS, R.C. Organizational development and transformation. Annual Review of Psychology. 1991, Vol. 42 Issue 1, p51. 28p.

PRETORIUS, J. The security Imaginary: explaining Military isomorphism. Security Dialogue, v. 39, n. 1, p. 97-118, 2008.

SCHEIN, E. Cultura organizacional e liderança. São Paulo: Atlas, 2009.

SCHMITT, V. G. H; COSTA, R. P. da; NETO, L. M. Desvendando a administração em ambientes militares. Coleção Meira Mattos/ Revista das Ciências Militares, n. 27, p. 1-15, 2012.

SCHMITT, V. G. H.; MARQUES, A. A. Práticas e proposições da carreira civil em Defesa. VII Encontro Nacional da Associação Brasileira de Estudos de Defesa. Belém - PA, 2013.

SECCHI, L. Modelos organizacionais e reformas da administração pública. Revista de Administração Pública, v. 43, n. 2. p. 347-369, 2009.

SILVA, F. de A. e; GONÇALVES, C. A. O processo de formulação e implementação de planejamento estratégico em instituições do setor público. Revista de Administração UFSM, v. 4, n. 3, p. 458476, set-dez, 2011.

SILVA, F. M. da; MELLO, S. P. T. de; TORRES, I. A. C. O que se discute sobre gestão por competências no setor público: um estudo preliminar das construções. Revista de Administração UFSM, v. 6, n. 4, p. 685-693, dez 2013.

VASCONCELLOS, C. A. R. de. Aproximação entre civis e militares com a criação do Ministério da Defesa. Dissertação de Mestrado em Administração Pública. Rio de Janeiro: EBAPE/FGV, 2011.

VIEIRA, P. R. Em busca de uma teoria de descentralização. Revista de Administração Pública, v. 46, n. 5, p. 1409-425, 2012. 